\title{
Maximizing the benefit of health workforce secondment in Botswana: an approach for strengthening health systems in resource-limited settings
}

\author{
This article was published in the following Dove Press journal: \\ Risk Management and Healthcare Policy \\ 16 May 2014 \\ Number of times this article has been viewed
}

\begin{abstract}
Jessica S Grignon ${ }^{1,2}$
Jenny H Ledikwe ${ }^{1,2}$

Ditsapelo Makati²

Robert Nyangah ${ }^{2}$

Baraedi W Sento ${ }^{2}$

Bazghina-werq Semo ${ }^{1,2}$

'Department of Global Health, University of Washington, Seattle, WA, USA; ${ }^{2}$ International Training and Education Center for Health, Gaborone, Botswana
\end{abstract}

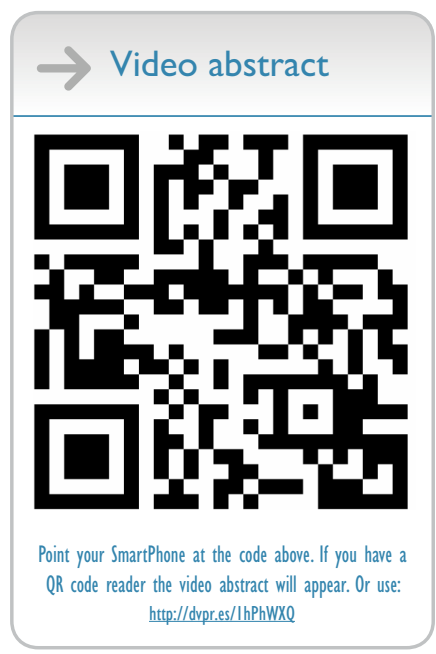

Correspondence: Bazghina-werq Semo PO Box AC46, ACH, Riverwalk, Gaborone, Botswana

Tel +2673900925

Fax +2673900952

Email bazsemo@uw.edu

\begin{abstract}
To address health systems challenges in limited-resource settings, global health initiatives, particularly the President's Emergency Plan for AIDS Relief, have seconded health workers to the public sector. Implementation considerations for secondment as a health workforce development strategy are not well documented. The purpose of this article is to present outcomes, best practices, and lessons learned from a President's Emergency Plan for AIDS Relief-funded secondment program in Botswana. Outcomes are documented across four World Health Organization health systems' building blocks. Best practices include documentation of joint stakeholder expectations, collaborative recruitment, and early identification of counterparts. Lessons learned include inadequate ownership, a two-tier employment system, and ill-defined position duration. These findings can inform program and policy development to maximize the benefit of health workforce secondment. Secondment requires substantial investment, and emphasis should be placed on high-level technical positions responsible for building systems, developing health workers, and strengthening government to translate policy into programs.
\end{abstract}

Keywords: human resources, health policy, health worker, HIV/AIDS, PEPFAR

\section{Introduction}

\section{Health system and human resource constraints in sub-Saharan Africa}

Although sub-Saharan Africa has experienced gains in major health indicators since the 1960s postcolonial era, the disparity between the population health of the region and the rest of the world has widened as gains were reversed by the HIV/AIDS epidemic. ${ }^{1,2}$ Sub-Saharan Africa remains the region most severely affected worldwide by HIV/ AIDS. ${ }^{3}$ HIV/AIDS and other health conditions continue to put an enormous burden on low- and middle-income countries, straining already-overstretched health systems. ${ }^{4}$ A major strain on the systems is a health workforce shortage resulting from increased workloads in providing HIV care and treatment, ${ }^{5,6}$ health worker emigration to the global market, and underinvestment in human resources because of cuts in public health expenditures. ${ }^{4,5}$ Sub-Saharan Africa will need to add approximately 1 million workers to meet the United Nations Millennium Development Goals. ${ }^{5}$

A variety of health workforce capacity-development strategies have been implemented globally to address health systems challenges in resource-limited settings. These strategies include a focus on restructuring human resources (HR) to enable a skill mix that matches the needs of the population, attracting and retaining health 
workers to rural areas to manage uneven distribution of $\mathrm{HR}$, and improving access to HR information for evidencebased policy development and implementation. ${ }^{5}$ Building human and organizational capacity for high performance is important for expansion of quality health services. ${ }^{7}$ Specific interventions include task-shifting, ${ }^{8-10}$ preservice and in-service training/mentoring, ${ }^{11}$ and global health fellowships. ${ }^{7,12,13}$ Global, donor-supported strategies for the attraction and retention of the health workforce include "pooling mechanisms" that outsource employment, 14 "top ups" of government salaries, ${ }^{14-16}$ and "secondment" of implementing partner staff to the public sector to provide technical support. ${ }^{16}$

The practice of secondment as a strategy for skills development is generally known as the temporary loan of an individual for mutual organizational and individual benefit. ${ }^{16-22}$ The secondment strategy implemented by global health initiatives (GHIs), particularly the President's Emergency Plan for AIDS Relief (PEPFAR), is frequently documented. ${ }^{16,23-28}$ There is, however, a gap in the literature regarding practical implementation considerations and critical success factors related to the use of secondment as a global health workforce development strategy. The purpose of this article is to present the outcomes, best practices, and lessons learned from the implementation of a PEPFAR-funded health workforce secondment program in Botswana.

\section{Health workforce secondment in Botswana}

Botswana, a middle-income country in sub-Saharan Africa, has a national HIV prevalence of $25 \%$ among adults of reproductive age (15-49 years). ${ }^{29,30}$ In 2010, the country's health workforce included approximately 15,500 health workers, with an estimated shortage of 10,000 health workers. ${ }^{31}$ Health workforce shortages in Botswana have created major gaps in the availability of quality healthcare because of factors such as increased HIV/AIDS-related workload, emigration and maldistribution of $\mathrm{HR}$, inadequate number of tertiary training institutions, and inadequate plans to attract and retain health workers. $^{29,31}$ To address HR shortages, the government of Botswana has worked closely with donors to implement a health workforce secondment program.

In 2011, PEPFAR supported more than 150 health worker positions $^{32}$ through direct salary support for approximately 85 government of Botswana positions and funding for seven implementing partners to employ and second approximately 75 positions to the Ministry of Health (MOH), Ministry of Local Government, University of Botswana (UB), and National AIDS Coordinating Agency. ${ }^{33}$ These secondments included five PEPFAR-identified categories of health workers: clinical care service providers, clinical service staff, managerial and support staff at a facility and community level, managerial and support staff at all levels of government, and community services staff. ${ }^{34}$

Since 2004, The International Training and Education Center for Health (I-TECH) in Botswana, a collaboration between the University of Washington and the University of California, San Francisco, has recruited and seconded 46 positions to two national host institutions, $\mathrm{MOH}$ and UB. I-TECH Botswana has seconded staff within four PEPFARdefined health care worker categories. The secondment process is initiated with the development of a job description by I-TECH Botswana in collaboration with the host institution and the donor. Recruitment and candidate selection are also a collaborative effort between these three parties. The successful candidate is hired by I-TECH Botswana and, as an employee, is governed by the organizational policies and structures within I-TECH Botswana as the legal employer and seconding organization. The employee is, however, embedded within the host institution and has a functional supervisor within the host institution to provide day-to-day oversight and guidance.

\section{Outcomes of the secondment program in strengthening the health system}

The outcomes of I-TECH Botswana's PEPFAR-funded secondment program are classified according to the relevant World Health Organization health system building blocks: service delivery, leadership and governance, health workforce, and health information systems (Table 1) ${ }^{35}$ Although these achievements are not attributable to the work of seconded staff alone, they represent accomplishments related to seconded staff leadership and joint collaborations with host institution colleagues.

\section{Health service delivery}

Sixteen seconded positions within the PEPFAR categories of clinical care providers and support staff have conducted health service delivery. These health workers were deployed at public health facilities as part of a national scale-up of voluntary medical male circumcision, an add-on HIV prevention strategy, and conducted a total of 6573 male circumcisions. ${ }^{36}$ This represents approximately $37 \%$ of all procedures conducted through PEPFAR-supported implementing partners 


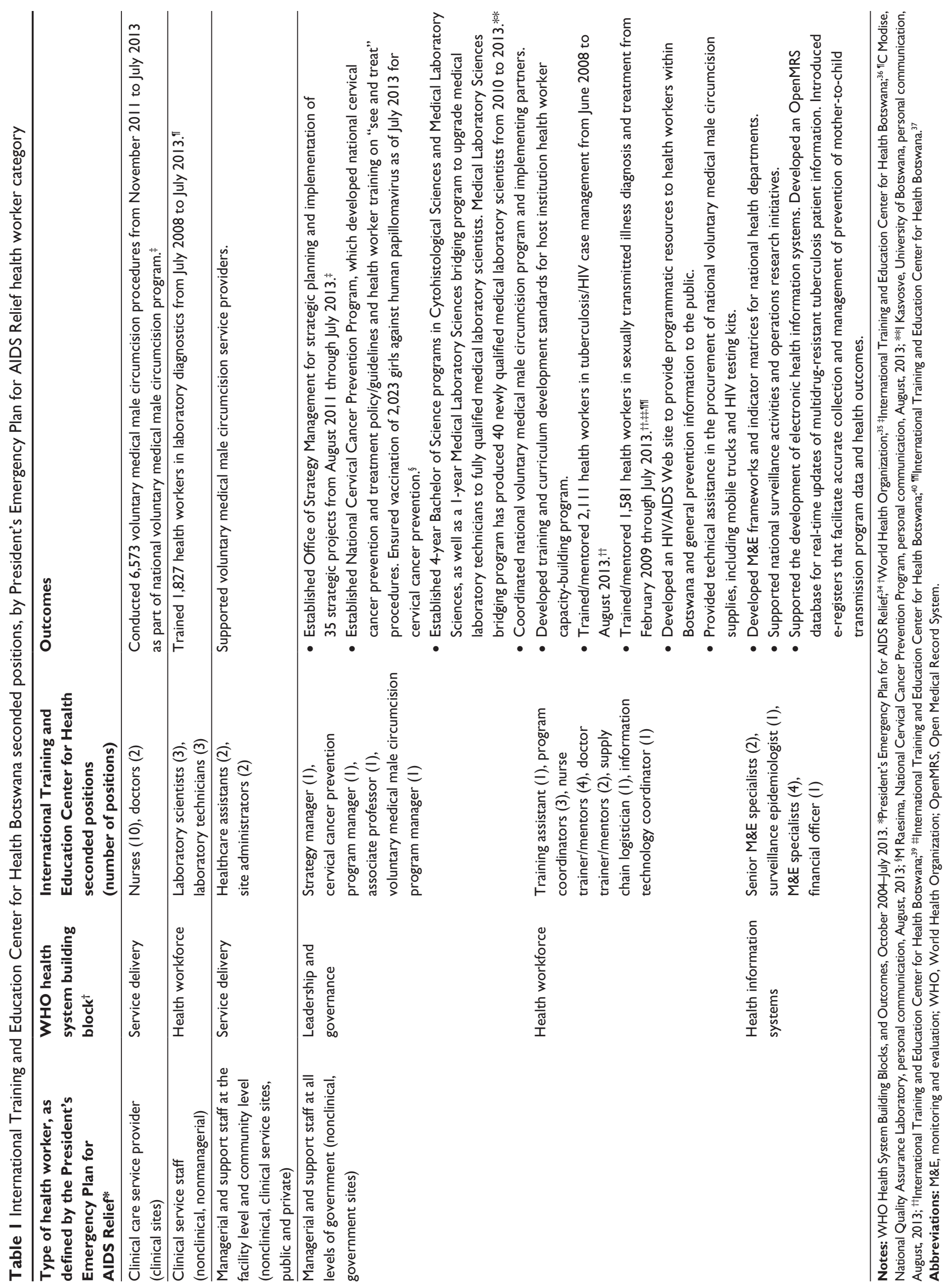


(R Manda, Centers for Disease Control Botswana, personal communication, August, 2013).

\section{Leadership and governance}

Four seconded positions have provided support in the area of leadership and governance at national host institutions, guiding new initiatives, coordinating national health programs, and building the capacity of the teams they manage. Some key outcomes have been achieved through seconding a manager to the MOH Office of Strategy Management. Through this position, the $\mathrm{MOH}$ has been able to develop its strategic plan, manage implementation of its strategy, and improve governance and control of programs through the implementation of 35 strategic projects. ${ }^{36}$ Another key outcome has been the establishment of the MOH National Cervical Cancer Program through the secondment of the National Cervical Cancer Program manager and programmatic support from multiple donors and partners. This program has been responsible for developing national cervical cancer prevention and treatment policy/guidelines and a health worker training program on "see and treat" procedures to reduce patient loss to follow-up. ${ }^{36}$ The program has ensured vaccination against human papillomavirus of 2,023 girls as part of a package of cervical cancer prevention efforts (M Raesima, National Cervical Cancer Prevention Program, personal communication, August, 2013).

\section{Health workforce}

A cornerstone of I-TECH's secondment program has been support for the health workforce building block. In keeping with the PEPFAR commitment to increase the number, quality, and relevance of health workers, ${ }^{11} 18$ seconded positions have been responsible for building health workforce capacity through preservice training, in-service training, and mentoring. Secondment of an associate professor to UB resulted in the establishment of 4-year Bachelor of Science programs in both cytohistological sciences and medical laboratory sciences, as well as a 1-year medical laboratory sciences bridging program to upgrade medical laboratory technicians to fully qualified medical laboratory scientists. ${ }^{36-38}$ The medical laboratory sciences bridging program produced 40 newly qualified medical laboratory scientists. ${ }^{38}$ Sixteen seconded positions have built health workforce capacity through the in-service training and mentoring of 2,111 health workers on the control, prevention, and treatment of tuberculosis $;{ }^{39} 1,581$ health workers on the diagnosis and treatment of sexually transmitted illnesses; ${ }^{39,40}$ and 1,827 health workers on strengthening laboratory diagnostics (C Modise, National Quality Assurance Laboratory, personal communication, August, 2013).

\section{Health information systems}

Eight seconded positions have contributed to national health information systems. A notable outcome through secondment of a senior monitoring and evaluation (M\&E) specialist to the $\mathrm{MOH}$ has been the development of M\&E frameworks and indicator matrices for national health departments to monitor strategic initiatives. Seconded M\&E specialists also strengthened health information systems through initiatives such as the development of an open source medical record system for real-time updates of multidrug-resistant tuberculosis patient information and the introduction of e-registers to facilitate accurate collection and management of prevention of mother-to-child transmission program data and health outcomes.

\section{Lessons learned and best practices: policy and practice considerations for secondment to strengthen health systems}

To achieve health systems gains from a secondment program, there are practical considerations for program implementation. I-TECH Botswana identified lessons learned and best practices to inform policy development and program planning that maximizes the benefit of health workforce secondment as a health systems strengthening approach. The lessons learned and best practices are categorized according to organizational roles and responsibilities, collaboration, and sustainability.

\section{Organizational roles and responsibilities}

One best practice for the secondment program was the development of memoranda of agreements (MOAs) to define the respective roles and responsibilities of the seconding organization and the national host institution. MOAs documented mutual expectations of technical assistance contributions, rights to data use, HR management roles, and essential equipment required. An MOA with one national host institution specified the engagement period for each seconded position; as a result, this facilitated seamless transition of all seconded staff to host institution employment. Pursuant to each MOA, a "secondment guide" was developed to provide detailed instructions regarding the supervision of seconded staff pertaining to areas such as compensation, leave management, and professional development. Although MOAs and secondment guides are best practices for role clarification between the seconding organization and host institution, a considerable investment of time and legal counsel was essential, and there were challenges establishing official documentation in a timely manner. 
Despite the presence of MOAs, a lesson learned is that ownership of secondments by national host institutions was challenging in some instances. Lack of ownership left seconded staff feeling unclear about their mandate and lines of reporting. Success of the position required continued ownership from all levels of management at the national host institution, and continued relationship-building and collaboration were essential for ensuring ownership.

\section{Collaboration}

Many best practices of the secondment program centered on ongoing collaboration among stakeholders. For example, maintaining a strong tripartite relationship among the donor, national host institution, and seconding organization proved critical during the initial planning, recruitment, and management of the secondment. The initial planning stage enabled the donor, national host institution, and seconding organization to discuss and agree on the position mandate and the health systems gap it addressed. A key component of establishing a joint mandate was a mutually agreed-on job description, which adequately served the needs defined by the host institution. This stakeholder team participated in a transparent, joint interview process of all shortlisted candidates, setting the individual up for success in his/her role.

Although the process was successful in defining the position mandate at the start, collaboration between the host institution and seconding organization in relation to HR systems and performance management was also a lesson learned. Secondment creates a two-tier employment system, which can be cumbersome to manage between the seconding organization as the legal employer and the national host institution where the employee carries out his/her duties. This includes duplicate HR systems, processes, and forms. A best practice was to align HR systems as closely as possible with the national host institution to reduce the organizational and individual burden. A best practice was the alignment of performance management tools with the national host institution; by accepting feedback via a host institution's performance-based reward system, this lessened the burden on supervisors and expedited the seconding organization's performance appraisal process.

Another best practice in collaboration is regular communication between the seconding organization and the national host institution. Biannual meetings to discuss policy considerations and invite feedback on progress of seconded positions stimulated two-way communication to address implementation issues. Another best practice is to ensure the donor is regularly updated regarding successes and challenges of the seconded position. Regular communication and maintenance of the tripartite relationship throughout the life of the secondment was essential for avoiding "mission creep," ensuring joint expectations were met, and addressing any shifts in donor priorities with the national host institution.

\section{Sustainability}

The importance of outlining the national host institution and donor's vision for position duration, whether for shortterm technical assistance to build capacity and strengthen systems or for absorption into the host institution structure was another lesson learned. When the commitment from the national host institution was unclear and ill-defined related to its specific plans to absorb the position, positions were ended on termination of donor funding. This created a gap in the workforce, which can have a drastic effect on the health system, and the original investment may lose its value. In cases in which the position mandate included skills transfer, it was important to identify who should be gaining the benefits of the mentorship. A lesson learned was that skills may not be adequately transferred to the national host institution if local counterparts were not identified or if staff turnover remained a problem.

The best practice for ensuring sustainability of secondments, particularly midlevel project posts, was to align remuneration packages with national host institutions for positions transitioning to permanent employment by the host institutions. This ensured remuneration was not an inhibiting factor for the national host institution to absorb the position. Despite this best practice, there were factors that negatively affected the ability to plan transitions well, particularly dwindling financial resources for both the national host institution and the donor. A decline in PEPFAR funds accelerated PEPFAR-funded secondment transition planning, and national host institutions have not been able to align HR plans with this development because of limited financial resources and a government-mandated hiring freeze.

\section{Discussion}

Secondment is acknowledged in the literature at a policy level as a gap-filling human resources for health strategy practiced by GHIs, ${ }^{16,23,25-28}$ yet little is documented at the programmatic level regarding functional implementation of donor-funded secondments to maximize their benefit. I-TECH Botswana's experience demonstrated that secondment can be a successful strategy to strengthen health systems in resource-limited settings. 


\section{Secondment goes beyond "gap-filling" to strengthening the system}

Secondments offer a structured approach to building the capacity of the health workforce. Although position mandates differ, seconded positions not only fill the human resources gap for the period of funding provided but also develop the capacity of the health system by training and mentoring other health care workers, implementing national health strategy, and strengthening M\&E systems for evidencebased planning. These system-strengthening benefits have been noted in relation to secondment programs in South Africa, ${ }^{15}$ Scotland, ${ }^{41}$ and the United Kingdom. ${ }^{19,20}$ A desirable attribute of secondment experienced by I-TECH Botswana was the ability to recruit and attract international human resources for high-level technical expert positions in cases where technical skills were scarce locally. Mayhew et al also highlight the important role that high-level secondments played in strengthening health systems in South Africa. ${ }^{15}$ This enabled national host institutions to attract highly skilled individuals who were qualified to build the capacity of counterparts. A critical attribute of secondment is enabling flexibility within the system: when national host institutions are constrained by hiring freezes, they are able to engage human resources for health to plan initiatives and develop systems for the future.

\section{Maximizing the benefit of secondment requires investment and management}

To maximize the potential benefit of a global health workforce secondment program, it requires substantial investment on the part of the seconding institution in areas such as leadership, supervision, legal counsel, and stakeholder involvement. The importance of these attributes of a successful secondment experience were also highlighted by Dryden and Rice in relation to a program in the United Kingdom. ${ }^{17}$ The best practices and lessons learned indicate that ensuring clarity of organizational roles and responsibilities is critical to a successful program.

The importance of clarifying of roles and responsibilities has also been noted in relation to multiple different systems, such as health information systems ${ }^{42}$ and healthcare delivery systems, ${ }^{43}$ as well as in the use of secondment programs to strengthen human resources for health systems. ${ }^{21}$ Furthermore, strengthening stakeholder collaboration and ensuring sustainability of the intervention were also found to be important. These findings are similar to those reported from Zambia by Hanefeld and Musheke, who also found that if the long-term funding of seconded position is not considered, then there can be negative consequences within the health systems. ${ }^{16}$

One of the key findings of I-TECH Botswana's program was the importance of tripartite collaboration (donor, seconding organization, and host institution) and documentation of respective organizational roles and responsibilities through MOAs, which has been reported by others in the literature. ${ }^{15,21}$ Through the implementation of this secondment program in Botswana, as well as through work reported by others, there are multiple factors facilitating health worker retention and sustainability of secondment, including provision of clearly defined job descriptions, ${ }^{19}$ a vision beyond the period of secondment, ${ }^{44}$ systematic documentation of national host institution plans to absorb seconded positions, and early identification of counterparts for skills-transfer.

\section{Recommendations}

With a decline in host government budgets and GHI funding, particularly for secondments, ${ }^{32}$ the benefits of these positions must be maximized to sustain improvements in health system capacity to meet Millennium Development Goals. Emphasis should be placed on high-level technical positions responsible for strategic planning, building systems, transferring skills, and developing the capacity of health workers. Key focal areas should be strengthening government capacity in HR planning and policy development and translating policy into program implementation, particularly with regard to management, deployment, and retention of newly trained health workers. ${ }^{11,44}$ GHIs should consider the importance of documenting commitments with host institutions, in terms of the vision, mechanisms, and parameters of a secondment program before designation of funds to promote sustainability. Further research is needed regarding GHI-funded secondments from the perspectives of national host institutions, seconding organizations, and donors to implement evidence-based human resources for health strategies that best meet host government needs into the future.

\section{Limitations}

A limitation of this article is that it only presents the experience of a single organization in a single resource-limited setting. It does not represent the views of the national host institutions or donors. There may be attributes of the program that are specific to the Botswana context. The specific programmatic outcomes achieved by the seconded staff are limited in generalizability. Nevertheless, the best practices and lessons learned help fill a void in the literature regarding practical implementation con- 
siderations and success factors related to the use of secondment as a global health workforce development strategy.

\section{Acknowledgments}

The authors acknowledge the contributions of I-TECH seconded staff and stakeholders from $\mathrm{MOH}, \mathrm{UB}$, Centers for Disease Control Botswana, and I-TECH, who provided important information for this manuscript. This work was supported by PEPFAR through funding to the University of Washington and I-TECH from the US Department of Health and Human Services, Health Resources and Services Administration Global HIV/AIDS Bureau (cooperative agreement U91 HA06801), and from the Centers for Disease Control and Prevention (cooperative agreement U2 GPS001824).

\section{Author contributions}

Jessica S Grignon participated in management of the secondment program and manuscript writing. Jenny H Ledikwe participated in supervision of seconded staff and manuscript writing. Robert Nyangah participated in supervision of seconded staff and manuscript revision. Baraedi W Sento and Ditsapelo Makati participated in manuscript revision. Bazghina-werq Semo participated in oversight and management of the secondment program and manuscript writing. All authors read and approved the final manuscript.

\section{Disclosure}

The authors report no conflicts of interest in this work.

\section{References}

1. Adetunji J, Bos ER. Levels and trends in mortality in Sub-Saharan Africa: an overview. In: Jamison DT, Feachem RG, Makgoba MW, et al, editors. Disease and Mortality in Sub-Saharan Africa. 2nd ed. Washington, DC: World Bank; 2006.

2. World Health Organization. Global HIV/AIDS Response: Epidemic Update and Health Sector Progress Toward Universal Access. Geneva: World Health Organization; 2011. Available from: http://whqlibdoc.who. int/publications/2011/9789241502986_eng.pdf. Accessed May 1, 2013.

3. Joint United Nations Programme on HIV/AIDS. Global Report: UNAIDS Report on the Global AIDS Epidemic. Geneva: Joint United Nations Programme on HIV/AIDS; 2012. Available from: http:/www.unaids. org/en/media/unaids/contentassets/documents/epidemiology/2012/ gr2012/20121120_unaids_global_report_2012_with_annexes_en.pdf. Accessed May 1, 2013.

4. World Health Organization Maximizing Positive Synergies Collaborative Group, Samb B, Evans T, et al. An assessment of interactions between global health initiatives and country health systems. Lancet. 2009;373(9681):2137-2169.

5. Chen L, Evans T, Anand S, et al. Human resources for health: overcoming the crisis. Lancet. 2004;364(9449):1984-1990.

6. Tawfik L, Kinoti SN. The Impact of HIV/AIDS on Health Systems and the Health Workforce in Sub-Saharan Africa. Washington, DC: Support for Analysis and Research in Africa (SARA) Project, Academy for Educational Development. Available from: http://pdf.usaid.gov/pdf_docs/ PNACX273.pdf. Accessed May 1, 2013.
7. Vian T, Richards SC, McCoy K, Connelly P, Feeley F. Public-private partnerships to build human capacity in low income countries: findings from the Pfizer program. Hum Resour Health. 2007;5:8.

8. Ledikwe JH, Kejelepula M, Maupo K, et al. Evaluation of a wellestablished task-shifting initiative: the lay counselor cadre in Botswana. PLoS One. 2013;8(4):e61601.

9. World Health Organization. Treat, Train, and Retain: The AIDS and health workforce plan. Geneva: World Health Organization; 2006. Available from: http://www.who.int/hiv/pub/meetingreports/ TTRmeetingreport2.pdf. Accessed June 23, 2013.

10. Ledikwe JH, Reason LL, Burnett SM, et al. Establishing a health information workforce: innovation for low- and middle-income countries. Hum Resour Health. 2013;11(1):35.

11. Palen J, El-Sadr W, Phoya A, et al. PEPFAR, health system strengthening, and promoting sustainability and country ownership. J Acquir Immune Defic Syndr. 2012;60 Suppl 3:S113-S119.

12. Lansang MA, Dennis R. Building capacity in health research in the developing world. Bull World Health Organ. 2004;82(10): 764-770.

13. Godlee F. WHO fellowships - what do they achieve? BMJ. 1995; 310(6972):110-112.

14. Vio F. Management of expatriate medical assistance in Mozambique. Hum Resour Health. 2006;4:26.

15. Mayhew SH, Doherty J, Pitayarangsarit S. Developing health systems research capacities through north-south partnership: an evaluation of collaboration with South Africa and Thailand. Health Res Policy Syst. 2008;6:8.

16. Hanefeld J, Musheke M. What impact do Global Health Initiatives have on human resources for antiretroviral treatment roll-out? A qualitative policy analysis of implementation processes in Zambia. Hum Resour Health. 2009; 7:8.

17. Dryden H, Rice AM. Using guidelines to support secondment: a personal experience. J Nurs Manag. 2008;16(1):65-71.

18. Ntata PRT. Capacity building through secondment of staff: a possible model in emergencies? Dev Pract. 2007;17(1):104-113.

19. Greig JI. Secondments in health care quality assurance. Int J Health Care Qual Assur. 1994;7(5):12-13.

20. Kedward A, Jones E. Surviving secondments. Nurs Manag (Harrow). 2008;15(7):12-14

21. Hamilton J, Wilkie C. An appraisal of the use of secondment within a large teaching hospital. J Nurs Manag. 2001;9(6):315-320.

22. Budgen C, Gamroth L. An overview of practice education models. Nurse Educ Today. 2008;28(3):273-283.

23. Dräger S, Gedik G, Dal Poz MR. Health workforce issues and the Global Fund to fight AIDS, Tuberculosis and Malaria: an analytical review. Hum Resour Health. 2006;4:23.

24. Bisika T, Buch E, Mathole T, Parsons A, Sanders D. South Africa: The effects of Global Health Initiative funding for HIV/AIDS on the health system. In: Interactions Between Global Health Initiatives and Health Systems: Evidence from Countries. Geneva: World Helath Organization; 2009:168-180. Available from: http://www.who.int/healthsystems/ publications/MPS_academic_case_studies_Book_01.pdf. Accessed August 19, 2013.

25. Hanefeld J. Impact Beyond Intent: The Role of Global Health Initiatives in the Policy Implementation of Antiretroviral Treatment Roll-out in Zambia and South Africa. London: Department for International Development; 2008. Available from: http://r4d.dfid.gov.uk/PDF/Outputs/ HIV_AIDS/ghi_comparative_paper.pdf. Accessed August 19, 2013.

26. Hanefeld J. The impact of Global Health Initiatives at national and sub-national level - a policy analysis of their role in implementation processes of antiretroviral treatment (ART) roll-out in Zambia and South Africa. AIDS Care. 2010;22 Suppl 1:93-102.

27. Sullivan J, Busang L, Manthe LRG, Moeti TL. Expanding Access to HIV Care and Prevention through Successful Public-Private Partnerships: Lessons Learned from Botswana. In: Marlink R, Teitelman S, editors. From the ground up. Vol III. Washington, DC: Elizabeth Glaser Pediatric AIDS Foundation; 2009;442. 
28. Fowler A. Civil Society Capacity Building and the HIV/AIDS Pandemic: A Development Capital Perspective and Strategies for NGOs. The Hague: PSO Capacity Building in Developing Countries; 2004. Available from: http://www.impactalliance.org/file_download.php?location= S_U\&filename=11546909101Alan_Fowler-2004.pdf. Accessed August 19, 2013.

29. Ministry of Health. National Health Service Situation Analysis report. Gaborone: Government of Botswana; 2009.

30. Central Statistics Office, National AIDS Coordinating Agency. 2008 Botswana AIDS Impact Survey III: Statistical Report. Gaborone: Government of Botswana; 2009. Available from: http://www.hiv.gov.bw/ sites/default/files/documents/baisiii_report\%5B1\%5D.pdf. Accessed April 2, 2014

31. Ministry of Health. Integrated Health Service plan: A strategy for changing the health sector for healthy Botswana 2010-2020. Gaborone: Government of Botswana; 2010. Available from: http://www.moh.gov. bw/Publications/policies/Botswana\%20IHSP\%20Final\%20HLSP.pdf. Accessed April 2, 2014.

32. Stash S, Cooke J, Fisher M, Kramer A. Competing Pressures for US PEPFAR in Botswana: Rising Ambitions, Declining Resources. Washington, DC: Center for Strategic and International Studies; 2012. Available from: http://csis.org/files/publication/121128_Stash_PEPFARBotswana_Web.pdf. Accessed May 1, 2013.

33. Schaan, C, PEPFAR Botswana Coordinator. Government of Botswana Posts Supported by PEPFAR Funds (official letter to Ministry of Health). Gaborone: PEPFAR Botswana; 2011.

34. The United States President's Emergency Plan for AIDS Relief (PEPFAR). Country Operational Plan (COP) Guidance. Washington, DC: United States Government; 2012. Available from: http://www.pepfar. gov/documents/organization/198957.pdf. Accessed August 19, 2013.
35. World Health Organization. Monitoring the Building Blocks of Health Systems: A Handbook of Indicators and Their Measurement Strategies. Geneva: World Health Organization; 2010. Available from: http:// www.who.int/healthinfo/systems/WHO_MBHSS_2010_full_web.pdf. Accessed April 26, 2013.

36. International Training and Education Center for Health (I-TECH) Botswana. Quarterly Reports to US Centers for Disease Control Botswana. Gaborone: University of Washington/I-TECH; 2010-2013.

37. I-TECH Botswana. Annual Reports to US Centers for Disease Control Botswana. Gaborone: University of Washington/I-TECH; 2007-2009.

38. Magowe M, Ledikwe JH, Thankane K, et al. An innovative educational approach to develop medical laboratory scientists in Botswana. $A d v$ Med Educ Pract. 2014;5:73-81.

39. I-TECH Botswana. TrainSMART Database. Gaborone: University of Washington/I-TECH; 2013.

40. I-TECH. Annual Reports to Health Services and Resources Administration. Seattle: University of Washington/I-TECH; 2005-2006.

41. Cheseldine S, Brown M, Wilkie F. Secondment as a means of practice development for Community Learning Disability Nurses working with children. Nurse Educ Today. 2010;30(7):692-696.

42. Ledikwe JH, Grignon J, Lebelonyane R, et al. Improving the quality of health information: a qualitative assessment of data management and reporting systems in Botswana. Health Res Policy Syst. 2014;12:7.

43. Yakam JC, Gruénais ME. Involving new actors to achieve ART scaling-up: difficulties in an HIV/AIDS counselling and testing centre in Cameroon. Int Nurs Rev. 2009;56(1):50-57.

44. Martínez J, Martineau T. Rethinking human resources: an agenda for the millennium. Health Policy Plan. 1998;13(4):345-358.
Risk Management and Healthcare Policy

\section{Publish your work in this journal}

Risk Management and Healthcare Policy is an international, peerreviewed, open access journal focusing on all aspects of public health, policy, and preventative measures to promote good health and improve morbidity and mortality in the population. The journal welcomes submitted papers covering original research, basic science, clinical \& epidemio-

\section{Dovepress}

logical studies, reviews and evaluations, guidelines, expert opinion and commentary, case reports and extended reports. The manuscript management system is completely online and includes a very quick and fair peerreview system, which is all easy to use. Visit http://www.dovepress.com/ testimonials.php to read real quotes from published authors. 